\title{
ON LASER POWDER-BED FUSION OF ADDITIVELY MANUFACTURED AISi10Mg ALLOY: TENSILE PROPERTIES AND STRUCTURE CHARACTERIZATION
}

\author{
Y. Rosenthal1, Y. Apelstein'1, I. Rosenthal2,3, D. Ashkenazi4*, \\ A. $\operatorname{Stern}^{1,5}$

\begin{abstract}
${ }^{1}$ Department of Mechanical Engineering, Afeka Academic College of Engineering, Tel Aviv, 6910701, Israel ${ }^{2}$ Department of Materials Engineering, Ben-Gurion University of the Negev, Beer Sheva 8410501, Israel ${ }^{3}$ Production Systems Group, National Institute of Standards and Technology, Gaithersburg, MD 20899 USA ${ }^{4}$ School of Mechanical Engineering, Tel Aviv University, Ramat Aviv 6997801, Israel

${ }^{5}$ Department of Materials Engineering, Ben-Gurion University of the Negev, Beer Sheva 8410501, Israel

* Corresponding author's e-mail address: dana@eng.tau.ac.il
\end{abstract}

\begin{abstract}
The mechanical properties of additive manufactured laser powder-bed fusion ( $L$ $P B F)$ AlSilOMg specimens, built with the chessboard building strategy and followed by three thermal treatments, were evaluated using standard mechanical testing in tension. Metallography and fractography tests were conducted to reveal the microstructure and connect them to the properties in various stages of the research. A strong relationship between hatching strategy, build direction and loading direction was found and it was concluded that the mechanical properties of the alloy in the modified $T 5\left(200^{\circ} \mathrm{C}\right)$ thermal condition are similar to the as-built condition for the concept strategy. The mechanical properties are similar albeit the differences found in the fracture faces of $X$ and $Z$ specimens. The similarity of the mechanical properties in the $X$ and $Z$ directions also suggests that the additively manufacturing (AM) L-PBF process yields fairly homogenous mechanical properties of AlSilOMg (excluding the T5 treated alloy). The mechanical properties and the microstructure obtained were compared to an equivalent alloy AM L-PBF manufactured using an EOS(C) system with a different hatching strategy. The three different thermal conditions, employed in this research, provided insight into the mechanical behavior under different strategies. Understanding these changes in mechanical properties, as a result of these thermal conditions, allows for tailoring AM parts for engineering applications having various requirements. The onset of the elastic-plastic deformation and the possible effects of the hatching strategy on the elastic-plastic deformation and the strain hardening behavior were also discussed.
\end{abstract}

KEYWORDS: Additive manufacturing, AlSi10Mg alloy, Laser powder-bed fusion, Mechanical properties, Fractography.

\section{INTRODUCTION}

Al-Si alloys are of significant interest and widely used in many important industries, such as the automotive and aerospace industries. This is due to their combination of relatively high strength and low density alongside the ability to manufacture complex shapes with thin walls most commonly through casting [1], [2]. The typical microstructure of conventionally cast Al-Si alloys normally contains relatively coarse acicular silicon as well as different $\mathrm{Mg}$ precipitates; the rough $\mathrm{Si}$ secondary phase is harmful to the ductility and is typically refined [3].

Additive manufacturing (AM) is a promising technology that has brought great opportunities for the design and production of metallic components with high geometrical complexity [4]-[6]. One of the most popular AM processes is the selective laser melting with a powder-bed system. In this process, thinlayered powders of metals are constantly spread and are fused by laser beam irradiation. Recently laser powder-bed fusion (L-PBF) AM technique, which has high heating and cooling rates (up to $10^{6} \mathrm{~K} / \mathrm{s}$ ), has been used to improve the microstructure of $\mathrm{Al}-\mathrm{Si}$ alloys and to significantly improve the mechanical properties of those materials. AlSi10Mg alloy is compatible with the L-PBF AM technique as it is close to the eutectic $\mathrm{Al}-\mathrm{Si}$ composition leading to 
high castability and weldability properties, as well as exhibiting fully dense parts. The mechanical properties of AM AlSi10Mg alloy are higher or at least comparable to conventional high-pressure diecast material which can be attributed to the extremely fine microstructure as well as eutectic silicon particles that comprise the AlSi10Mg, resulting from the AM process [7]-[11]. Several papers have been published recently describing the mechanical properties and microstructures observed in laser-fabricated PBF samples of AlSi10Mg alloy and other Al-Si alloys [12]-[18]. However, the results and interpretations differ significantly. In order to maximize the performance and functionality of specific components, the AM L-PBF industry currently faces fundamental issues of the AlSiloMg material's mechanical properties tailoring related to the material processability as well as post-processing [19]-[21]. In this study, three metallurgical conditions were examined and compared, in order to understand the effect of different heat treatments on the mechanical properties.

The aim of this research was to examine the mechanical properties in tension of AM L-PBF AlSi10Mg standard specimens in two build directions and three thermal conditions, and to investigate the correlation between mechanical properties and microstructure. The novelty of the current research is that it may provide new data for structural applications of L-PBF Al alloys.

\section{EXPERIMENTAL PART}

The main elements of this research were planned and directed towards its leading objective: exploring the mechanical properties in tension of AM AlSi10Mg alloy in two built directions and three thermal condition (for each built direction). The four stages of the experimental procedures were: (1) specimen preparation, (2) revealing the as-received macrostructure, (3) tensile testing, and (4) fractographic analysis. The results are discussed and compared to an equivalent alloy AM L-PBF manufactured using an EOS@ system with a different hatching strategy.

\subsection{Specimen Preparation}

AM of AlSi10Mg parts powders were performed on a Concept Laser@ M2 L-PBF machine, with build envelope dimensions of $250 \times 250 \times 350 \mathrm{~mm}^{3}$. The M2 apparatus has an Nd: YAG fiber laser operated in continuous wave mode with a maximum power of $360 \mathrm{~W}$. Processing was performed under an argon (below $0.1 \%$ oxygen content) atmosphere. A chessboard-scan hatching strategy was used to produce the rod-shaped parts (Fig. 1); the layers were divided into several $5.6 \mathrm{~mm}$ islands. Each square was shaped by raster scanning of the laser and then the beam scans were carried out around the perimeters.
For each consecutive layer, the square pattern was shifted by $1 \mathrm{~mm}$ in $\mathrm{X}$ - and Y-direction and rotated by 90 ० to exclude the build-up of discontinuities between islands perimeters. The scanning strategy is illustrated in figure 1 .

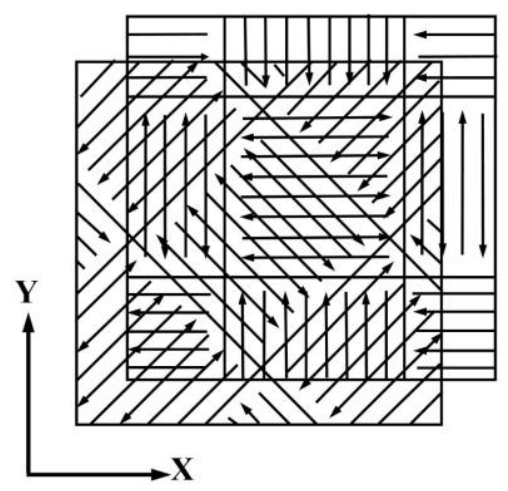

Fig. 1. Schematic illustration of the chessboard hatching strategy used to produce the rod-shaped parts. The layers are divided into several $5.6 \mathrm{~mm}$ squares. For each consecutive layer, the squares are shifted by $1 \mathrm{~mm}$ in the $\mathrm{X}$ and $\mathrm{Y}$-directions and the scanning direction inside the islands is rotated by $90^{\circ}$.

Three metallurgical conditions were examined in this research: (a) as-built; (b) 2 hours at $300^{\circ} \mathrm{C}$ (also known as T5 treatment); (c) 2 hours at $200^{\circ} \mathrm{C}$ (a modified T5 treatment). Heat treatments in air were applied following the machining of the tensile specimens.

\subsection{Macrostructure Evaluation}

A computerized Nikon $($ SMZ800 light microscope system, equipped with a TV camera, was used to evaluate the typical chessboard macrostructure morphology, following the application of metallography procedures. The chessboard macrostructure morphology is demonstrated in figure $3 \mathrm{a}$ and $3 \mathrm{~b}$ in comparison to the commonly used $67^{\circ}$ hatching strategy (Fig. 3c) [8], [17].

\subsection{Mechanical Testing and Fractography}

Uniaxial quasi-static tensile tests were conducted according to ASTM E8/E8M-16a standard test method for tension testing of metallic materials [22] on three specimens for each metallurgical condition. Tensile tests were conducted on a computerized 5-ton E43.504 MTS@ $\odot$ universal testing system equipped with an alignment fixture. All the tests were performed at a constant crosshead velocity of $0.5 \mathrm{~mm} / \mathrm{min}$, equivalent to an engineering strainrate of $8.34 \times 10^{-3} \mathrm{~s}^{-1}$. As an extensometer was not able to be utilized due to the loading line configuration limitations, displacement data was obtained from the crosshead position sensor and used to calculate strain and elongation to fracture. Hirox (C- 
RH-2000 multi-focal high-resolution light microscope (LM) system was used to examine the fracture face morphology following the tensile tests. This multi- focal digital LM has high pixel density, and very low image noise. Moreover, it combines large working distance and width depth of field.
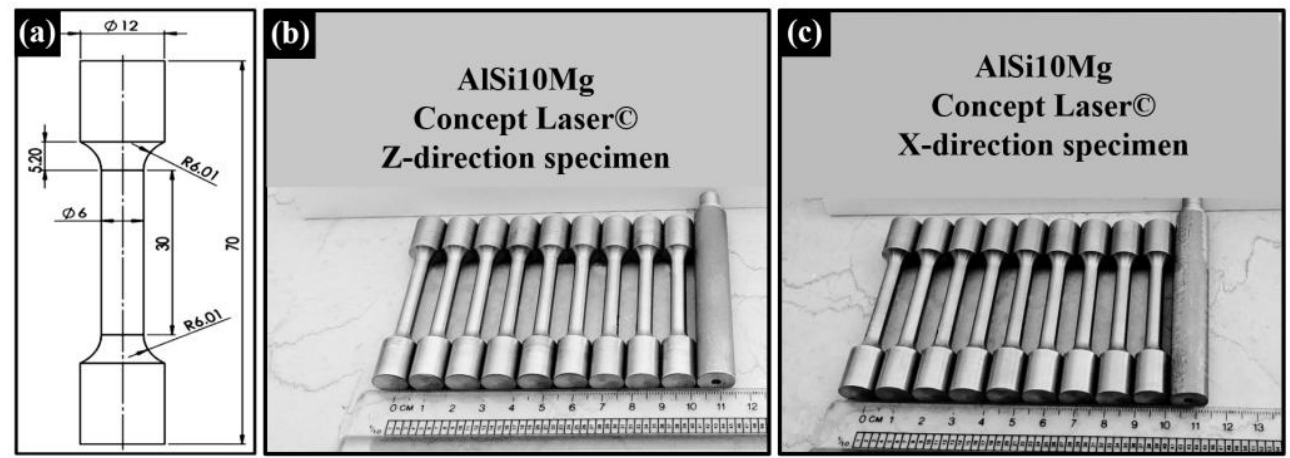

Fig. 2. Build setup: (a) specimen drawing; (b) images of the as-machined AM L-PBF AlSi10Mg tensile specimens printed in the vertical Z direction; (c) images of the as-machined AM L-PBF AlSi10Mg tensile specimens printed in the horizontal $\mathrm{X}$ direction. The cylinders shown in (b) and (c) were used for as-built metallographic examination
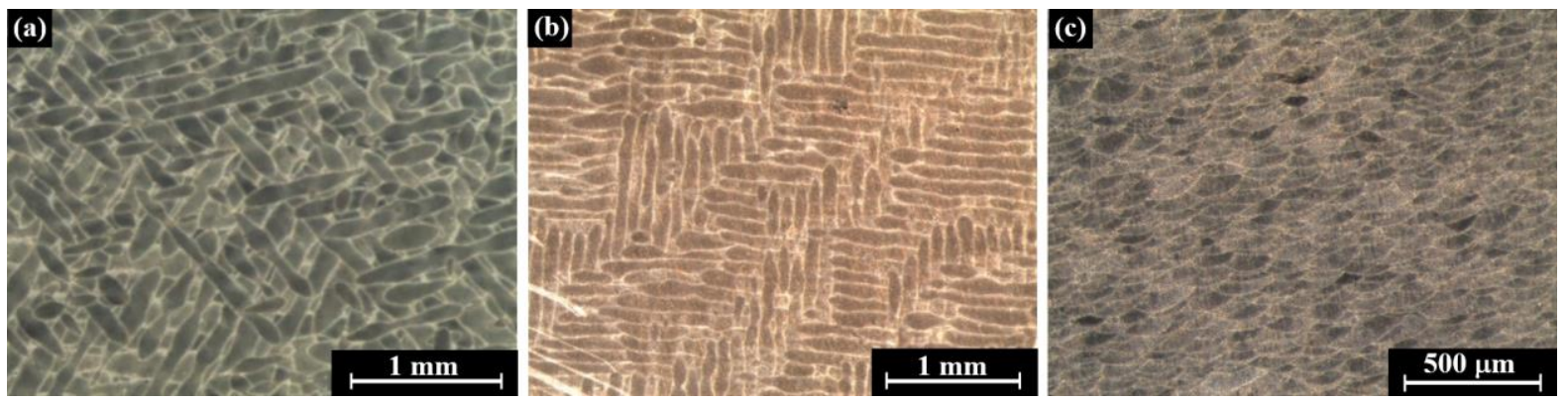

Fig. 3. (a) The building direction of Concept Laser@ chessboard track segments morphology in AM L-PBF

AlSi10Mg Z specimen is perpendicular to the photo plane; (b) The building direction of Concept Laser@ chessboard fish-scale morphology in X specimen is parallel to the photo plane; and (c) The building direction of EOS $\odot 67^{\circ}$ strategy track segments morphology in $\mathrm{Z}$ specimen is perpendicular to the photo plane

\section{RESULTS}

\subsection{Mechanical Testing}

Graphs of room-temperature tensile elastic-plastic portions of the engineering stress-strain curves for AM L-PBF AlSi10Mg specimens built in $\mathrm{X}$ and $\mathrm{Z}$ direction, for all the applied metallurgical conditions (as-built, modified $\mathrm{T} 5$ at temperatures of $200^{\circ} \mathrm{C}$ and $300^{\circ} \mathrm{C}$ ), are shown in figure 4 . Room temperature proportional limit, UTS and elongation-to-fracture values in tension are presented in table 1 (calculated from the stress strain curves). A comparison between the stress-strain curves, obtained from Concept Laser@ and EOS $\odot$ strategies AM specimens, built in the $\mathrm{Z}$ direction, is presented in figure 5 for all the thermal conditions discussed here. The results of the EOS@ curves were obtained in a previous research [17].

Table 1. Room temperature mechanical parameters in tension calculated from the stress strain curves (Fig. 5). ${ }^{¥}$ As an extensometer was not able to be operated, the total elongation of the AM L-PBF AlSilOMg specimen gage was measured after fracture relatively to the initial gage length.

\begin{tabular}{|c|c|c|c|c|}
\hline Built Direction & Heat Treatment & \begin{tabular}{|c|} 
Proportional Limit \\
{$[\mathrm{MPa}]$}
\end{tabular} & $\begin{array}{c}\text { UTS } \\
{[\mathrm{MPa}]}\end{array}$ & $\begin{array}{c}\text { Total Elongation } \\
\text { to fracture, [\%] }\end{array}$ \\
\hline $\mathrm{X}$ & \multirow[b]{2}{*}{ As-built } & 100 & $464 \pm 2$ & 7.1 \\
\hline $\mathrm{Z}$ & & 100 & $468 \pm 1$ & 5.4 \\
\hline$X$ & \multirow{2}{*}{ T5 $\left(300^{\circ} \mathrm{C}\right)$} & 100 & $310 \pm 3$ & 9.2 \\
\hline $\mathrm{Z}$ & & 100 & $342 \pm 5$ & 6.5 \\
\hline $\mathrm{X}$ & \multirow{2}{*}{$\begin{array}{l}\text { Modified T5 } \\
\left(200^{\circ} \mathrm{C}\right)\end{array}$} & 125 & $459 \pm 3$ & 6.8 \\
\hline $\mathrm{Z}$ & & 125 & $478 \pm 1$ & 3.0 \\
\hline
\end{tabular}



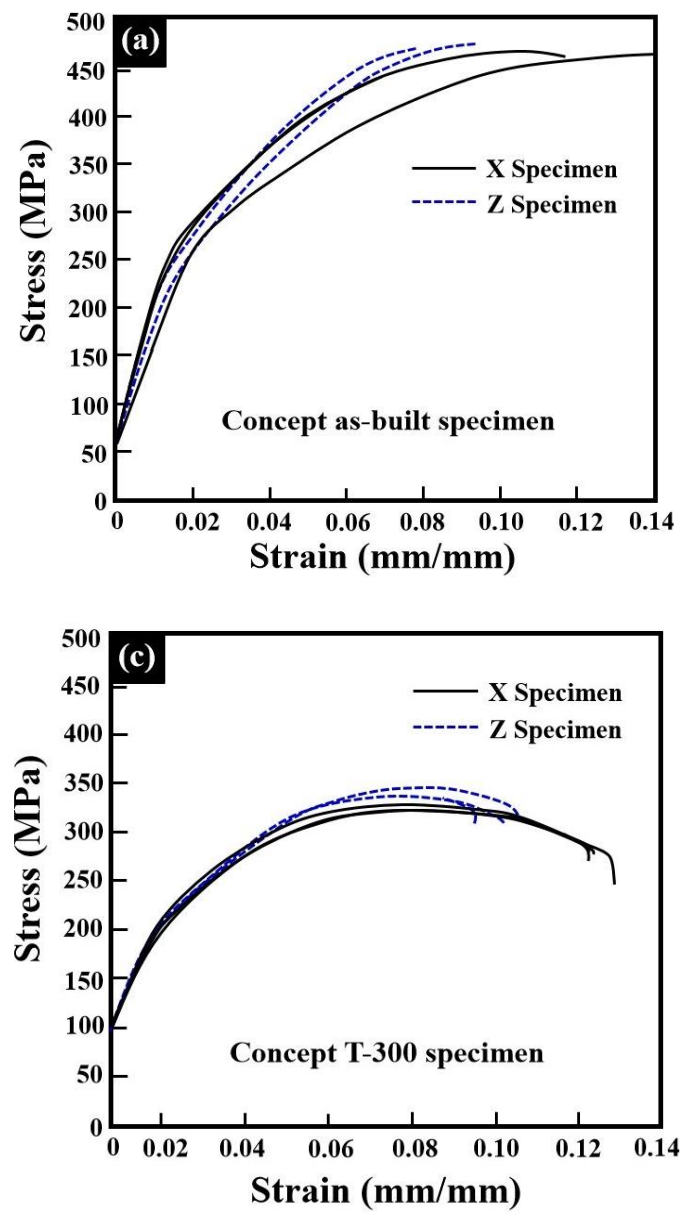

Fig. 4. Elastic plastic deformation curves in tension for AM and heat treated AM L-PBF AlSi10Mg specimens,

(a) as-built; (b) modified $\mathrm{T} 5\left(200^{\circ} \mathrm{C}\right)$; and (c) T5 $\left(300^{\circ} \mathrm{C}\right)$

\subsection{Fractography}

Multi-focal LM revealed the fracture face morphology in the as-built AM L-PBF AlSi10Mg X-axis parallel to the Y-Z plane as shown in Fig. 6 and the fracture face morphology in the as-built $Z$-axis, parallel to $X$ $\mathrm{Y}$ the plane as shown in figure 7 . The same observations are shown for modified T-5 $\left(200^{\circ} \mathrm{C}\right)$ specimens (Fig. 8 and 9) and for T5 $\left(300^{\circ} \mathrm{C}\right)$ specimens (Fig. 10 and 11). The fractography results are discussed in section 4.2 of the discussion part.

\section{DISCUSSION}

\subsection{Analysis of the Mechanical Testing Results}

The first issue observed when analyzing the mechanical behavior of AM AlSi10Mg specimens (produced with the same thermal condition), was surprisingly the similar response to loading of specimens built in the $\mathrm{X}$ direction comparing to $\mathrm{Z}$ specimens (Table 1). As shown schematically in figure 12 , the integration of a complicated
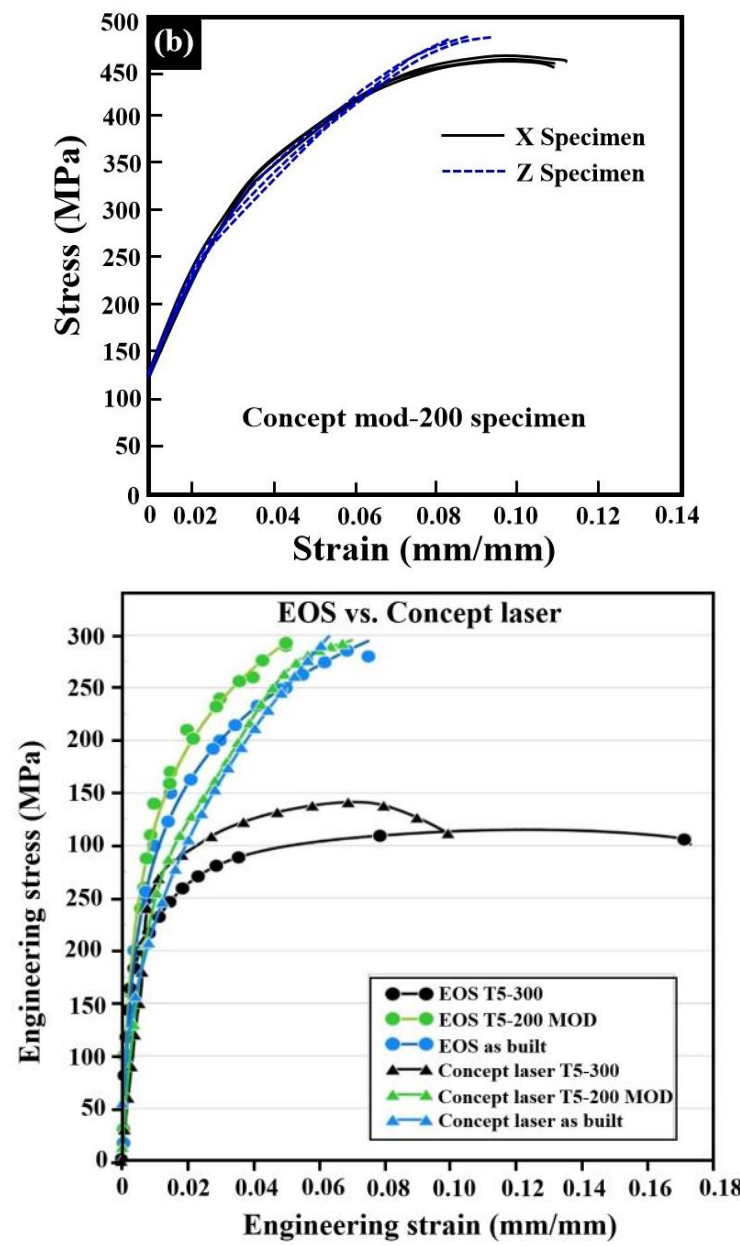

Fig. 5. Stress-strain curves, representing the Concept Laser(C) chessboard strategy compared to the EOSC scanning stripes strategy, in the $\mathrm{Z}$ direction, for all the thermal conditions and testing directions

configuration, consisting of loads applied to different macrostructures, was not straight forward at first observation. It was assumed that AM parts might exhibit a "loading-direction sensitive" mechanical behavior. Should we consider the strength of AM parts in terms of "building-layers separation-strength in tension" ("building-layers" stands for track segments originating from the scanning of the laser beam, as shown in figure $11 \mathrm{c}$, representing the fracture face of $\mathrm{Z}$ specimens) or "the building-layers shear-strength"?

Regardless, it is clear that both hatching strategy types (EOS@ or Concept Laser@) produce parts having a complicated meso-structure, which are subjected to complicated stress and strains states, even when an external load is applied solely along "traditional" axes. Observations from stress-strain curves for the as-built and heat treated samples are presented below; keeping in mind that: (a) loadingline in tensile tested X-specimens is parallel to layers and perpendicular to building direction and (b) loading-line in tensile tested Z-specimens is perpendicular to layers and parallel to building direction. 

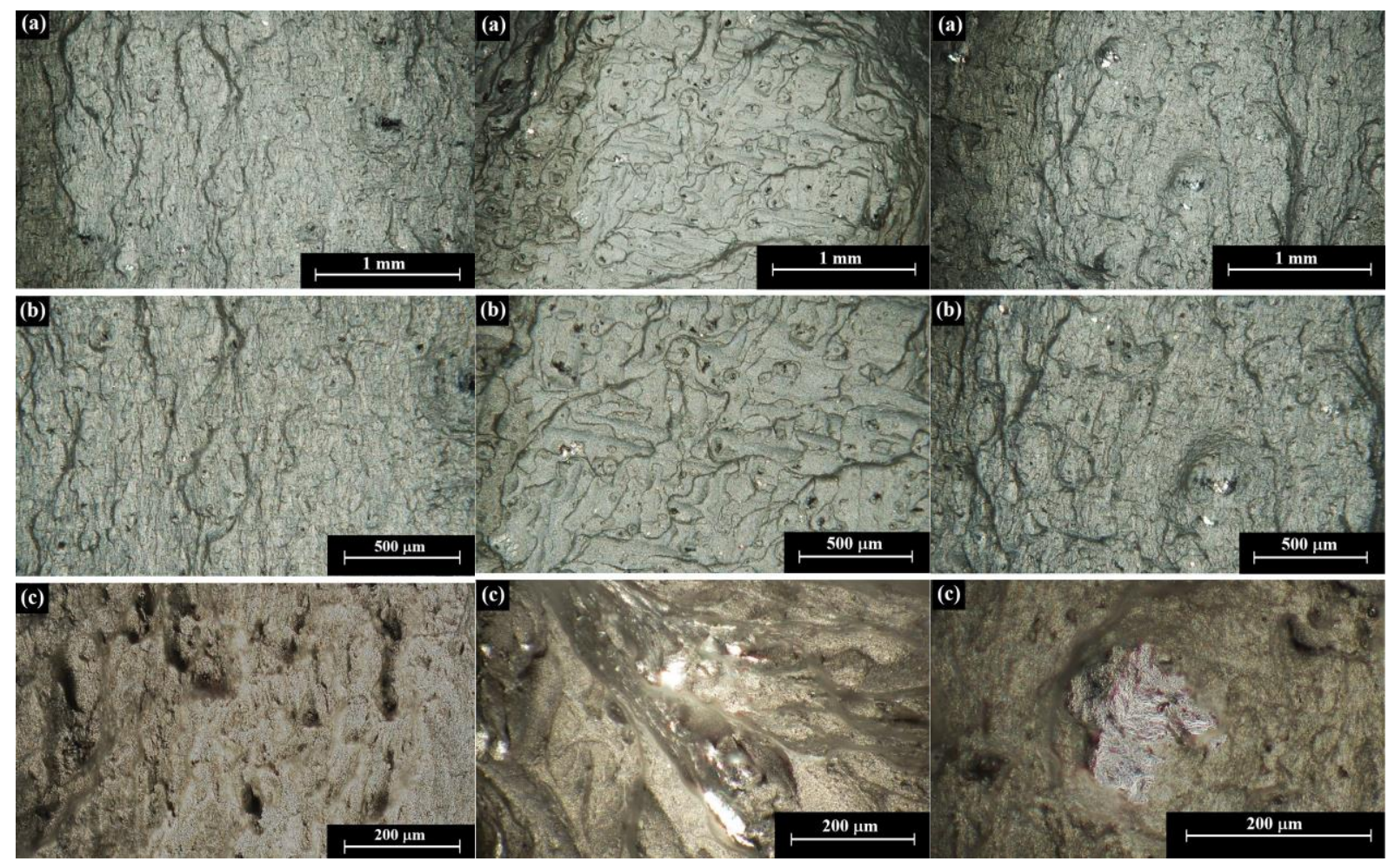

Fig. 6. Multi-focal LM observation of the fracture face morphology in the as-built AM L-PBF AlSi10Mg $\mathrm{X}$-axis: a) general view; b) and c) higher magnifications (fracture face is parallel to $\mathrm{Y}-\mathrm{Z}$ plane)
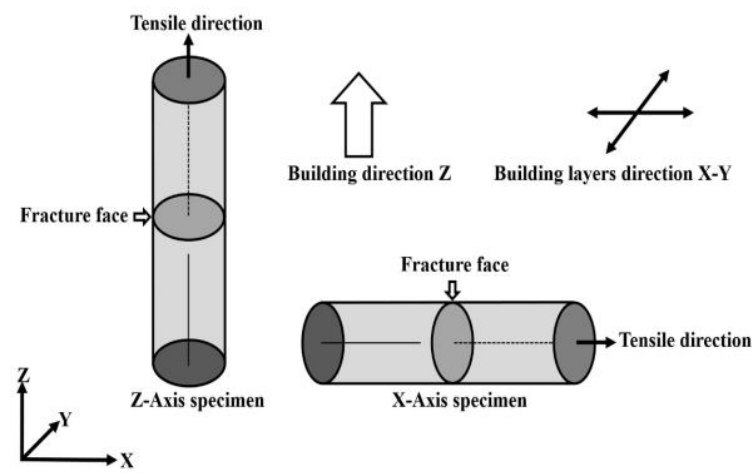

Fig. 12. Schematic drawing showing the interconnected factors of the tensile specimen build production (hatching strategy and "built layer" directions), and the corresponding tensile test layout (loading direction), affecting the mechanical properties results

In figure 12 it can be noticed that layers of metals powder are spread and then fused by laser beam in the horizontal X-Y plane (turning to laser track segments upon cooling). Then, the process proceeds in the $\mathrm{Z}$ direction, forming the chessboard structure.
Fig. 7. Multi-focal LM observation the fracture face morphology in s-built AM L-PBF AlSi10Mg Z-

axis: a) general view; b) and c) is parallel to $\mathrm{X}-\mathrm{Y}$ plan)
Fig. 8. Multi-focal LM observation of the fracture surface morphology in AM L-PBF AlSi10Mg modified

$\mathrm{T}-5\left(200^{\circ} \mathrm{C}\right) \mathrm{X}$-axis: a) general view; b) and c) higher magnifications (fracture face is parallel to $\mathrm{Y}-\mathrm{Z}$ plane)

\subsubsection{Experimental Notes on the Onset of Elastic-Plastic Deformation}

The onset value of elastic-plastic deformation, the proportional limit, observed at AM L-PBF AlSi10Mg in $\mathrm{X}$ and $\mathrm{Z}$ as-built and $\mathrm{T} 5\left(300^{\circ} \mathrm{C}\right)$ specimens was $100 \mathrm{MPa}$. The proportional limit observed in $\mathrm{X}$ and $\mathrm{Z}$ specimens that underwent the modified T5 $\left(200^{\circ} \mathrm{C}\right)$ heat treatment was $125 \mathrm{MPa}$. The proportional limit values for $\mathrm{X}$ and $\mathrm{Z}$ as-built and T5 treatment specimens could possibly suggest similar structural response to loading regardless of their different structurelloading combinations: Specimens that were built along $\mathrm{X}$-axis are subjected to the deformation mode of layers-shear as a result of tensile loading, while $\mathrm{Z}$ specimens, subjected to deformation mode of layers-separation as the loading line in this case, are perpendicular to the layers.

As-built specimens were not exposed to any heat treatment. On the other hand, the influence of the combinations of loadinglbuilding directions dependency can be supported by possible temperature effects on yielding of $\mathrm{X}$ and $\mathrm{Z}$ specimens exposed to heat treatments at $200^{\circ} \mathrm{C}$ and $300^{\circ} \mathrm{C}$. The same proportional limit was measured for both $\mathrm{X}$ and $\mathrm{Z}$ specimens, for each heat treatment. The measured proportional limit values were $125 \mathrm{MPa}$ and $100 \mathrm{MPa}$ for modified $\mathrm{T} 5\left(200^{\circ} \mathrm{C}\right)$ and $\mathrm{T} 5\left(300^{\circ} \mathrm{C}\right)$ specimens, 
respectively. It was assumed that temperature effects on the interactions of $\mathrm{Si}$ particles, and pre-existing dislocation network in deformed AlSi10Mg contribute to the proportional limit, and later to the elastic-plastic portion of the stress-strain curve. A rational explanation for any possible relationship between the proportional limit and the hatching-strategies । building-directions \ thermal-conditions \ loadingdirections is outside the scope of the present discussion and might be the subject of a future research.
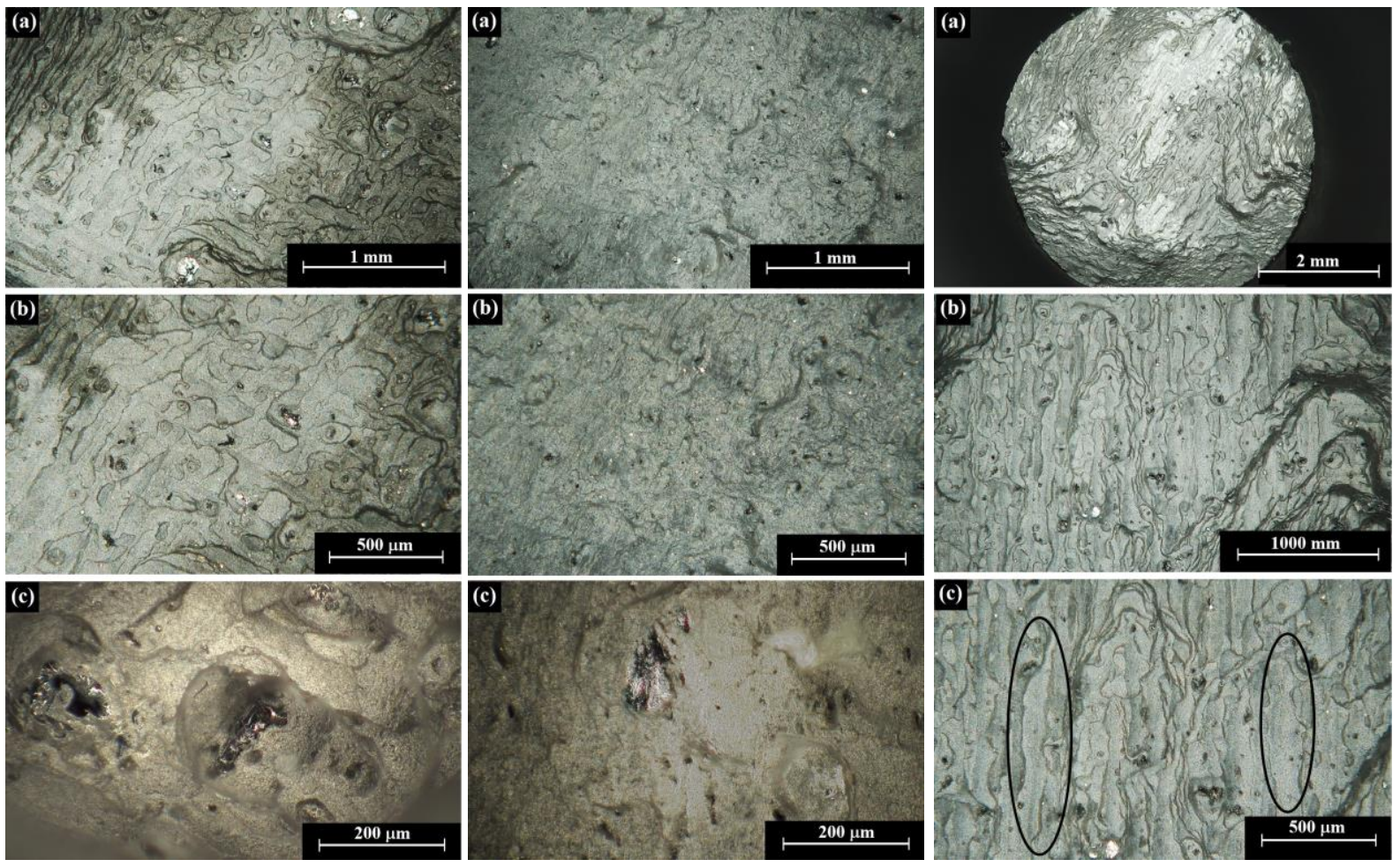

Fig. 9. Multi-focal LM observation of the fracture surface morphology in AM L-PBF AlSi10Mg modified

Fig. 10. Multi-focal LM observation of the fracture surface morphology in AM L-PBF AlSi10Mg T-5

$\mathrm{T}-5\left(200^{\circ} \mathrm{C}\right) \mathrm{Z}$-axis: a) general view; $\left(300^{\circ} \mathrm{C}\right) \mathrm{X}$-axis: a) general view; b)

b) and c) higher magnifications and c) higher magnifications

Fig. 11. Multi-focal LM observation of the fracture surface morphology in AM L-PBF AlSi10Mg T-5 $\left(300^{\circ} \mathrm{C}\right) \mathrm{Z}$-axis (the fracture face is parallel to X-Y plane; typical track (fracture face is parallel to $\mathrm{X}-\mathrm{Y}$ plane) (fracture face is parallel to $\mathrm{Y}-\mathrm{Z}$ plane) segments are marked in figure 11c)

\subsubsection{The Effect of Elastic-Plastic Deformation and Strain Hardening}

As-built AM L-PBF AlSi10Mg Z specimens show a higher degree of strain hardening, starting from a $100 \mathrm{MPa}$ and ending at similar ultimate tensile stress (UTS) values measured in $\mathrm{X}$ specimens. The total elongation measured in the $\mathrm{X}$ direction was somewhat higher than the total elongation in the $\mathrm{Z}$ direction.

Modified T5 $\left(200^{\circ} \mathrm{C}\right) \mathrm{X}$ and $\mathrm{Z}$ specimens show similar stress-strain behavior starting at $125 \mathrm{MPa}$ proportional limit and ending at UTS higher by 20 $\mathrm{MPa}$ for $\mathrm{Z}$ specimens. The degree of strain hardening was the same for $\mathrm{X}$ and $\mathrm{Z}$ specimens. It can be concluded here that the modification of $\mathrm{T} 5$ from $300^{\circ} \mathrm{C}$ to $200^{\circ} \mathrm{C}$ heat treatment hold temperature, resulted in the AlSi10Mg alloy having closer mechanical properties, as compared to as-built condition. $\mathrm{T} 5\left(300^{\circ} \mathrm{C}\right) \mathrm{X}$ and $\mathrm{Z}$ specimens results exhibit completely different mechanical properties comparing to the previous results. This heat treatment, commonly known as a stress-relieving treatment actually alleviates residual stresses, but, on the other hand, dramatically changes the elastic-plastic behavior of the alloy, comparing to the as-built condition. Both $\mathrm{X}$ and $\mathrm{Z}$ exhibit lower UTS (about $340 \mathrm{MPa}$ for $\mathrm{Z}$ specimens and $310 \mathrm{MPa}$ for $\mathrm{X}$ specimens). The total elongation to fracture was $9.2 \%$ for $\mathrm{T} 5\left(300^{\circ} \mathrm{C}\right) \mathrm{X}$ specimens - about $30 \%$ higher comparing to the total elongation to fracture measured in as-built $X$ specimens, suggesting the reason is mainly the existence of an almost completely annealed micro-structure.

Comparing the $\mathrm{Z}$ specimens Concep Laser@ to EOS $\odot 67^{\circ} \mathrm{C}$ hatching strategy mechanical properties, no significant differences are revealed except for the total elongation values measured in $\mathrm{T} 5\left(300^{\circ} \mathrm{C}\right)$ specimens (about 100\% higher values in EOS@).

\subsection{Fractography Observations}

An attempt was made to find a correlation between the features observed on the fracture faces and the corresponding mechanical properties of the AM L- 
PBF AlSi10Mg alloy in each direction and for all the heat treatments. In figures 6 to 11 (three magnifications of the fracture surfaces for each builddirectionlthermal condition) we demonstrate that the fracture faces of $\mathrm{X}$ specimens comparing to $\mathrm{Z}$ specimens are completely different. The main features observed in the fracture faces of $\mathrm{Z}$ specimens, in all the thermal conditions, are the laser track segments. Respectively, the examination of $\mathrm{X}$ specimens, in all the thermal conditions, reveal very similar features for all the thermal conditions specimens manufactured in the $\mathrm{X}$ or $\mathrm{Z}$ directions. We assumed that the additively manufactured specimens would exhibit different mechanical properties if tensile loads were directed parallel or perpendicular to the "building-layers". However, the values of mechanical properties obtained for the as-built and modified T5 $\left(200^{\circ} \mathrm{C}\right) \mathrm{X}$ and $\mathrm{Z}$ specimen (Table 1) suggest that in these cases the AM process and the following thermal treatment (for modified T5 specimens) yields fairly homogenous mechanical properties.

Although the fracture faces observed in $\mathrm{X}$ and $\mathrm{Z}$ specimens, with the $\mathrm{T} 5\left(300^{\circ} \mathrm{C}\right)$ heat treatment, show the same features discussed before, their mechanical properties differ from the properties of the other specimens tested. The plastic deformation stresses are considerably lower comparing to as-built and modified $\mathrm{T} 5\left(200^{\circ} \mathrm{C}\right)$ specimens. It can be assumed that the annealed structure enables the existence of distinctive changes in the features of the specimen cross section, subjected to tensile loads, and these changes can be associated with weak points through which the fracture originates/propagates more easily (in the annealed structure) leading to much lower strength and higher degree of ductility (UTS of 310 $\mathrm{MPa}$ and total elongation of $9.2 \%$ for $\mathrm{X}$ specimens and $340 \mathrm{MPa}$ and total elongation of $6.5 \%$, respectively, for $\mathrm{Z}$ specimens). Close values were obtained in EOS@ $\mathrm{T} 5\left(300^{\circ} \mathrm{C}\right) \mathrm{Z}$ specimens: low values of UTS (320 MPa) and total elongation of $18 \%$ (Fig. 5).

\section{CONCLUSIONS}

Following the discussion on the strong relationship between hatching strategy, build direction and loading direction (mechanical properties and fractography results), it was concluded that the mechanical properties of the AM L-PBF AlSi10Mg alloy in the modified $\mathrm{T} 5\left(200^{\circ} \mathrm{C}\right)$ thermal condition are similar to the as-built condition for the concept strategy. It was emphasized that the mechanical properties are similar albeit the differences found in the fracture faces of $X$ and $\mathrm{Z}$ specimens.

The similarity of the mechanical properties in the $\mathrm{X}$ and $\mathrm{Z}$ directions also suggests that the additively manufacturing L-PBF process yields fairly homogenous mechanical properties of AlSi10Mg (excluding the T5 treated alloy).

Comparing the $\mathrm{Z}$ specimens Concept Laser@ to
EOS $\odot 67^{\circ} \mathrm{C}$ hatching strategy mechanical properties, no significant differences are revealed except for the total elongation values measured in $\mathrm{T} 5\left(300^{\circ} \mathrm{C}\right)$ specimens (about $100 \%$ higher values in EOS $\odot$ ). It should be noted that some differences between the hatching strategies did exist, mainly manifested through elongation values. This suggests that some properties are more susceptible to changes due to macro features of the AM process.

The three different thermal conditions, employed in this research, provided insight into the mechanical behavior under different strategies. Understanding these changes in mechanical properties, as a result of these thermal conditions, allows for tailoring AM parts for engineering applications having various requirements.

\section{ACKNOWLEDGEMENTS}

The authors thank Sharon Tuvia (1982), Ltd. for providing the machining facilities. This research was supported by the Afeka Academic College of Engineering to whom the authors are grateful: Thanks are due to S. Maman, I. Kravchinski, A. Ulanov for their technical assistance and support. The authors are also grateful to D. Cvikel and M. Cohen, Leon Recanati Institute for Maritime Studies, University of Haifa, for their assistance with the LM-Hirox instrument.

\section{REFERENCES}

[1] Ye H., An overview of the development of Al-Si-alloy based material for engine applications, Journal of Materials Engineering and Performance 12.3, 2003, pp. 288-297.

[2] Wu J., Wang X. Q., Wang W., Attallah M. M., Loretto M. H., Microstructure and strength of selectively laser melted AlSi1OMg, Acta Materialia 117, 2016, pp. 311-320.

[3] Cáceres C. H., Davidson C. J., Griffiths J. R., The deformation and fracture behaviour of an Al-Si-Mg casting alloy, Materials Science and Engineering: A 197.2, 1995, pp. 171179.

[4] Ding Y., Muñiz-Lerma J. A., Trask M., Chou S., Walker A., Brochu M., Microstructure and mechanical property considerations in additive manufacturing of aluminum alloys, MRS Bulletin 41.10, 2016, pp. 745-751.

[5] Aboulkhair N. T., Everitt N. M., Maskery I., Ashcroft I., Tuck C., Selective laser melting of aluminum alloys, MRS Bulletin 42.4, 2017, pp. 311-319.

[6] Zhang Y., Wu L., Guo X., Kane S., Deng Y., Jung Y. G., Lee J. H., Zhang, J., Additive manufacturing of metallic materials: A review. Journal of Materials Engineering and Performance 27.1, 2018, pp. 1-13.

[7] Li W., Li S., Liu J., Zhang A., Zhou Y., Wei Q., Yan C., Shi Y., Effect of heat treatment on AlSi10Mg alloy fabricated by selective laser melting: Microstructure evolution, mechanical properties and fracture mechanism, Materials Science and Engineering: A 663, 2016, pp. 116-125.

[8] Rosenthal I., Stern A., Frage N., Strain rate sensitivity and fracture mechanism of AlSilOMg parts produced by selective laser melting, Materials Science and Engineering: A 682, 2017, pp. 509517.

[9] Trevisan F., Calignano F., Lorusso M., Pakkanen J., Aversa A., Ambrosio E., Lombardi M., Fino P., Manfredi D., On the selective laser melting (SLM) of the AlSilOMg alloy: process, microstructure, and mechanical properties, Materials 10.1, 2017, pp. 76. 
[10]Mertens A. I., Delahaye J., Lecomte-Beckers J. Fusion-based additive manufacturing for processing aluminum alloys: State-of-the-art and challenges, Advanced Engineering Materials 19.8, 2017, pp. 1700003.

[11]Fousová M., Dvorský D., Michalcová A., Vojtěch D., Changes in the microstructure and mechanical properties of additively manufactured AlSilOMg alloy after exposure to elevated temperatures, Materials Characterization 137, 2018, pp.119-126.

[12] Hadadzadeh A., Amirkhiz B. S., Li J., Mohammadi M., Columnar to equiaxed transition during direct metal laser sintering of AlSi1OMg alloy: effect of building direction, Additive Manufacturing 23, 2018, pp. 121-131.

[13] Mohammadi M., Asgari H., Achieving low surface roughness AlSi10Mg_200C parts using direct metal laser sintering, Additive Manufacturing, vol. 20, 2018, pp. 23-32.

[14] Maamoun A. H., Elbestawi M., Dosbaeva G. K., Veldhuis S. C., Thermal Post-processing of AlSilOMg parts produced by Selective Laser Melting using recycled powder, Additive Manufacturing 21, 2018, pp. 234-247.

[15] Rakesh C. S., Priyanka N., Jayaganthan R., Vasa, N. J., Effect of build atmosphere on the mechanical properties of AlSilOMg produced by selective laser melting, Materials Today: Proceedings 5.9, 2018, pp.17231-17238.

[16] Larrosa N. O., Wang W., Read N., Loretto M. H., Evans C., Carr J., Tradowsky U., Attallah M. M., Withers P. J., Linking microstructure and processing defects to mechanical properties of selectively laser melted AlSilOMg alloy, Theoretical and Applied Fracture Mechanics 98, 2018, pp. 123-133.

[17] Rosenthal, I., Shneck, R. and Stern, A., Heat treatment effect on the mechanical properties and fracture mechanism in AlSilOMg fabricated by additive manufacturing selective laser melting process, Materials Science and Engineering: A, 729, 2018, pp. 310322.

[18]Zhuo L., Wang Z., Zhang H., Yin E., Wang Y., Xu T., Li C., Effect of post-process heat treatment on microstructure and properties of selective laser melted AlSilOMg alloy, Materials Letters 234, 2019, pp. 196-200.

[19]Du Plessis A., Yadroitsev I., Yadroitsava I., Le Roux S. G., $X$-ray microcomputed tomography in additive manufacturing: a review of the current technology and applications, 3D Printing and Additive Manufacturing 5.3, 2018, pp. 227-247.

[20] Feigl T., Franke M., Körner C., Impact of build envelope on the properties of additive manufactured parts from AlSilOMg, Optics \& Laser Technology 111, 2019, pp. 51-57.

[21] Maamoun A., Xue Y., Elbestawi M., Veldhuis S., The Effect of Selective Laser Melting Process Parameters on the Microstructure and Mechanical Properties of Al6061 and AlSi10Mg Alloys, Materials 12(1), 2019, pp. 12.

[22]*** American Standards and Testing of Materials, ASTM E8/E8M-16a standard test method for tension testing of metallic materials, Revision 16A, August 1, 2016. 